\title{
Diabetes and visual impairment in sub-Saharan Africa: evidence from Cameroon
}

\author{
Ahmadou M Jingi', Jobert Richie N Nansseu2 ${ }^{2}$, Jean Jacques N Noubiap ${ }^{3,4}$, Yannick Bilong ${ }^{5}$, Augustin Ellong ${ }^{5}$
} and Côme Ebana Mvogo 5

\begin{abstract}
Background: "Vision 2020 - the right to sight" is a program which purpose is to eliminate avoidable blindness by the year 2020 through the implementation of concrete action plans at the national and district levels. Accordingly, baseline data are needed for the planning, monitoring, follow-up and evaluation of this program. The present study aimed to better characterize visual impairment and blindness in Cameroonian diabetics by providing with baseline data on the prevalence and main causes of these affections.
\end{abstract}

Methods: This was a hospital-based cross-sectional study, conducted from October 2004 to October 2006 at the Department of Ophthalmology of the Douala General Hospital, Cameroon. We included 407 diabetic patients who were referred from diabetes clinics for ophthalmologic evaluation. Ophthalmologic data included visual acuity, intra-ocular pressure, fundoscopy and fluorescein angiography.

Results: The prevalence of blindness and poor vision were respectively $12.3 \%$ and $17.4 \%$ with regard to the worst eyes. Fifty nine (14.5\%) patients were found with diabetic maculopathy, of whom 25.4\% (15/59) had poor vision, and 25.4\% (15/59) were blind. The prevalence of sight threatening retinopathy (severe non-proliferative and proliferative) was $17.4 \%$. The degree of visual impairment was comparable in both diabetic types ( $p=0.825)$, and it increased with the severity of retinopathy $(p<0.0001)$, as well as that of maculopathy $(p<0.0001)$. The prevalence of glaucoma was $15 \%(61 / 407)$ when considering the worst eyes. The severity of visual impairment increased with the severity of glaucoma ( $p=0.001)$. One hundred and twenty-one (29.7\%) patients presented with cataract irrespective of its location or severity. Cataract was significantly associated with poor vision and blindness $(p<0.0001)$. Hypertensive retinopathy (4.9\%), papillary ischaemia (2.7\%), vaso-occlusive eye disease $(2.5 \%)$, and age-related macular edema (2\%) were the other potential causes of visual impairment and blindness encountered the most in our setting. Age $\geq$ 50 years, male sex, duration of diabetes and hypertension variously increased the risk of having glaucoma, cataract, diabetic retinopathy or maculopathy.

Conclusion: Poor vision and blindness are frequent in Cameroonian diabetics, and their causes are similar to those reported by various other surveys: mainly cataract, glaucoma, diabetic retinopathy and maculopathy.

Keywords: Visual impairment, Diabetes, Diabetic retinopathy, Diabetic maculopathy, Cataract, Glaucoma, Cameroon, Sub-Saharan Africa

\footnotetext{
* Correspondence: noubiapjj@yahoo.fr

${ }^{3}$ Internal Medicine Unit, Edéa Regional Hospital, PO Box 100, Edéa, Cameroon

${ }^{4}$ Medical Diagnostic Center, Yaoundé, Cameroon

Full list of author information is available at the end of the article
} 


\section{Background}

There are 161 million people with visual impairment in the world, of whom approximately 37 million are blind [1]. Cataract accounts for most cases of blindness [1-5]. Blindness due to cataract is becoming widespread in developing countries owing to the increasing lifespan, the population getting thereby more and more aged [1]. Likewise, glaucoma is another important cause of visual impairment and blindness in developing countries, specifically in blacks where it occurs at a younger age ( $<40$ years) [6-9]. Cataract and glaucoma are, one and the other, two foremost ocular complications of diabetes besides diabetic retinopathy and maculopathy, and other potential blinding complications such as ischemic optic neuropathy, extra-ocular muscle palsy, iridocyclitis and rubeosis iridis [4]. Diabetes has reached epidemic proportions fuelled by an ageing population as well as the rapid increase of obesity, extending its greatest impact especially on developing countries' adults $[10,11]$. Lack of services to tackle the disease adds to the burden of avoidable blindness in developing countries.

The slogan "Vision 2020 - the right to sight" was launched in 1999, the purpose of which was to eliminate avoidable blindness by the year 2020, through the implementation of effective and concrete action plans at the national and district levels. Accordingly, baseline data are needed for the planning, monitoring, follow-up and evaluation of vision 2020 programs. But unfortunately, there is currently no baseline data on visual impairment and blindness in Cameroonian diabetic patients, this being not uncommon in many other Sub-Sahara African Countries. The present study aimed to determine the prevalence, characteristics and causes of visual impairment and blindness among Cameroonian diabetic patients.

\section{Methods}

\section{Ethics statement}

This study was approved by the National Ethics Committee of Cameroon. We obtained written informed consent from all the participants.

\section{Study population and setting}

The study was conducted from October 2004 through October 2006 in the Department of Ophthalmology of the Douala General Hospital, which has been extensively described elsewhere [12]. We included all diabetic patients who were referred from diabetes clinics for ophthalmologic evaluation during the study period. From these potential participants, we excluded those with incomplete data.

\section{Study procedure}

After collecting sociodemographic data such as age, sex and medical past history including type and duration of diabetes, a careful ophthalmologic evaluation was performed. Presenting and best-corrected visual acuity were measured using projection charts placed at a $6 \mathrm{~m}$ distance from the patient. Patients who could only count their fingers at $3 \mathrm{~m}$ and $1 \mathrm{~m}$ were attributed a visual acuity of $1 / 20$ and $1 / 50$ respectively. Visual acuity was recorded and classified according to the International Council of Ophthalmology (ICO) classification of visual impairment and blindness [13].

Intraocular pressure was measured by Goldman applanation tonometry incorporated into the biomicroscope, after instilling in each of the two eyes one drop of a local anaesthetic (amethocaine $0.5 \%$ or oxybupricaine $0.4 \%$ ), followed by the instillation of one drop of a diluted solution of sodium fluorescein 10\%. The biomicroscope was used with a +90 dioptres lens (Volk). Afterwards, the pupils were dilated with mydriatic drops, consisting in a combination of tropicamide $0.5 \%$ (Mydriaticum ${ }^{\circ}$ ) with phenylephrine $\mathrm{HCl}$ 10\% (Neosynephrine ${ }^{\oplus}$ ), instilled 3 times at a constant interval of 5 minutes. Fundoscopy was performed 45 minutes after the last drop has been instilled.

Biomicroscopy was performed with a +90 dioptres lens. Indirect ophthalmoscopy was performed as a supplement with a 3-mirrored lens in eyes with high risk of retinal detachment, to visualise the peripheral retina. Fluorescein angiography on its own was performed with a KOWA RC -XV2 angiograph as a complement to ophthalmoscopy. Serial photographs were taken with blue light after injecting $5 \mathrm{ml}$ of sodium fluorescein $10 \%$ into a good antebrachial vein, under strict asepsis.

\section{Measurements and definitions}

We used the following definitions, in keeping with the ICO classification of visual impairment and blindness [13]:

- Normal or near normal vision: VA 3/10 - 10/10.

- Mild poor vision or type I: VA $1 / 10-3 / 10$.

- Severe poor vision or type II: VA $1 / 20-1 / 10$.

- Legal blindness or type III: VA 1/50 - 1/20.

- Quasi total blindness or type IV: VA $<1 / 50$, Light perception $(+)$.

- Total blindness or type V: No light perception.

- Cataract: Any lens opacity.

- Glaucoma: (i) Intraocular pressure $>20 \mathrm{mmHg}$ with glaucomatous optic disc changes, (ii) Normal intraocular pressure with glaucomatous disc changes, (iii) Normal intraocular pressure, the patient being on long term anti-glaucomatous medication with or without glaucomatous disc changes.

- Diabetic retinopathy was classified as non-proliferative or proliferative.

- Diabetic maculopathy: Any retinal thickening in and around the macula.

- Visual impairment: Any poor vision or blindness. 


\section{Statistical methods}

Data were coded, entered and analyzed using the Statistical Package for Social Science (SPSS) version 20.0 for Windows (SPSS, Chicago, Illinois, USA). We described continuous variables using mean and standard deviation (SD) or median and interquartile range (IQR), and categorical variables using their frequency and percentage. The chi-square test or its equivalent was used to compare categorical variables. We calculated odds ratios (OR) with both univariate and multivariate logistic regression analyses while adjusting for confounders, in order to seek for factors influencing the occurrence of the different causes of visual impairment. A $p$ value less than 0.05 was considered statistically significant.

\section{Results}

On the whole, 407 diabetic subjects were retained, of whom $170(41.8 \%)$ were women and 358 (88\%) were type 2 diabetics (Table 1). Their ages ranged from 13 to 90 years, with a mean of 54.2 years $(S D=11.2)$, and they have been diagnosed with diabetes for a median duration of 5 years (IQR, 0.3-11) (Table 1).

As shown in Table 2, the prevalence of poor vision and blindness was respectively $11.8 \%$ and $14.0 \%$ for the right eyes, and $14.2 \%$ and $12.3 \%$ for the left ones. But when considering the most affected eye, the prevalence rates of poor vision and blindness were $12.3 \%$ and 17.4 respectively. Table 3 depicts the prevalence rates of diabetic retinopathy and maculopathy with regard to

Table 1 Background characteristics of study population $(\mathrm{N}=407)$

\begin{tabular}{ll}
\hline Characteristic & $\begin{array}{l}\text { Frequency (\%) or Mean (SD), } \\
\text { Median (IQR) }\end{array}$ \\
\hline Age (years) & $54.2(11.2)$ \\
Overall & $55.7(12.3)$ \\
Female & $53.2(10.3)$ \\
Male & \\
Gender & $237(58.2)$ \\
Male & $170(41.8)$ \\
Female & \\
Type of Diabetes & $49(12)$ \\
Type 1 & $358(88)$ \\
Type 2 & \\
Duration of diabetes (years) & $5(0.3-11)$ \\
Overall & $1(0-11)$ \\
Type 1 diabetes & $5(0.8-11)$ \\
Type 2 diabetes & \\
Hypertension & $246(40.4)$ \\
Absent & $161(39.6)$ \\
Present &
\end{tabular}

Table 2 Distribution of visual impairment

\begin{tabular}{llll}
\hline Category of vision & $\begin{array}{l}\text { Visual } \\
\text { acuity }\end{array}$ & $\begin{array}{l}\text { Right } \\
\text { eye } \\
\mathbf{n}(\%)\end{array}$ & $\begin{array}{l}\text { Left } \\
\text { eye } \\
\mathbf{n}(\%)\end{array}$ \\
\hline Normal or near-normal vision & $3 / 10-10 / 10$ & $302(74.2)$ & $299(73.5)$ \\
Mild poor vision (type I) & $1 / 10-3 / 10$ & $46(11.3)$ & $48(11.8)$ \\
Severe poor vision (type II) & $1 / 20-1 / 10$ & $11(2.7)$ & $10(2.4)$ \\
Legal blindness (type III) & $1 / 50-1 / 20$ & $11(2.7)$ & $13(3.2)$ \\
$\begin{array}{l}\text { Quasi-total blindness (type IV) } \\
\text { and total blindness (type V) }\end{array}$ & $<1 / 50$, LP*(+), & $37(9.1)$ & $37(9.1)$ \\
*LP: Light perception. & & &
\end{tabular}

*LP: Light perception.

visual acuity. Fifty nine (14.5\%) patients were found with diabetic maculopathy, of whom $25.4 \%(15 / 59)$ had poor vision (types I and II), and 25.4\% (15/59) were blind (types III, IV and V) with respect to the right eyes, these findings being similar in the case of the left eyes. As shown in Table 3, 60 (14.7\%) patients presented with proliferative retinopathy, $21.7 \%(13 / 60)$ of whom had poor vision (types I and II) whilst 41.7\% (25/60) were blind (types III, IV and V). The prevalence of sight threatening retinopathy (severe non-proliferative and proliferative) was $17.4 \%$. The degree of visual impairment was comparable in both diabetic types $(\mathrm{p}=0.825)$, and it increased with the severity of retinopathy $(\mathrm{p}<0.0001)$, as well as that of maculopathy ( $\mathrm{p}<0.0001)$.

On its own, the prevalence of glaucoma was $14.7 \%$ $(60 / 407)$ with concern to the right eyes (ocular pressure $>20 \mathrm{mmHg})$, with $16.7 \%(10 / 60)$ of these patients having a poor vision (types I and II), and 23.3\% (14/60) of them being blind (types III, IV and V) (Table 4). Neovascular glaucoma accounted for $6.7 \%(4 / 60)$ of all glaucomas, representing about $1 \%$ of all patients. The severity of visual impairment increased with the severity of glaucoma $(\mathrm{p}=0.001)$.

Twenty nine point seven per cent $(121 / 407)$ of participants presented with cataract irrespective of its location or severity (Table 5). When considering the right eye as the reference, $22.3 \%(27 / 121)$ of patients exhibiting cataract had poor vision (types I and II) while $21.5 \%$ (26/121) were blind (types III, IV and V). Cataract was significantly associated with poor vision and blindness $(\mathrm{p}<0.0001)$.

Table 6 presents other fundoscopic and angiographic findings that may result in poor vision and blindness. Hypertensive retinopathy (4.9\%), papillary ischaemia (2.7\%), vaso-occlusive eye disease (2.5\%), and age-related macular oedema $(2 \%)$ were other potential causes of visual impairment and blindness mostly encountered in our setting.

Correlates of causes of visual impairment are presented in Table 7 and Table 8. In multivariate analysis, an age greater than 50 years was associated with the risk of 
Table 3 Retinopathy and maculopathy with respect to visual acuity

\begin{tabular}{|c|c|c|c|c|c|}
\hline \multirow[b]{2}{*}{ Category of vision } & \multicolumn{3}{|l|}{$\begin{array}{l}\text { Retinopathy } \\
\text { n (\%) }\end{array}$} & \multicolumn{2}{|l|}{$\begin{array}{l}\text { Maculopathy } \\
\text { n (\%) }\end{array}$} \\
\hline & None $(n=243)$ & Non-proliferative $(n=104)$ & Proliferative $(n=60)$ & Absent $(n=348)$ & Present $(n=59)$ \\
\hline Normal or near-normal vision & $208(85.6)$ & $72(69.2)$ & $23(38.3)$ & $274(78.7)$ & $29(49.1)$ \\
\hline Mild poor vision & $18(7.4)$ & $21(20.2)$ & $7(11.7)$ & $36(10.3)$ & $10(17.0)$ \\
\hline Severe poor vision & $3(1.2)$ & $3(2.9)$ & $5(8.3)$ & $6(1.7)$ & $5(8.5)$ \\
\hline Legal blindness & $7(2.9)$ & $1(1.0)$ & $3(5)$ & $8(2.3)$ & $3(5.1)$ \\
\hline $\begin{array}{l}\text { Quasi-total blindness and } \\
\text { total blindness }\end{array}$ & $7(2.9)$ & $7(6.7)$ & $22(36.7)$ & $24(6.9)$ & $12(20.3)$ \\
\hline$p$ value & $<0.0001$ & & & $<0.0001$ & \\
\hline
\end{tabular}

having a severely impaired vision (at least severe poor vision) (OR: 6.03, 95\% CI 2.98-12.20; $p<0.001$ ), a cataract (OR: 3.44, 95\% CI 2.21-5.38; $p<0.001$ ) and a diabetic retinopathy (OR: 1.79, 95\% CI 1.20-2.67; $p=0.004$ ). Females were less likely to have a diabetic retinopathy (OR: 0.59, 95\% CI 0.42-0.84; $p=0.003$ ) and a maculopathy (OR: $0.53,95 \%$ CI $0.35-0.83 ; p=0.005$ ). A duration of diabetes greater than 10 years was associated with the presence of glaucoma (OR: 1.76, 95\% CI 1.16-2.68; $p=0.008$ ), cataract (OR: 1.42, 95\% CI 1.02-1.99; $p=0.035$ ), diabetic retinopathy (OR: 2.94, 95\% CI 2.06-4.20; $p<0.001$ ) and maculopathy (OR: 3.96, 95\% CI 2.48-6.35; $p<0.001$ ). Hypertensive patients were at higher risk of having glaucoma (OR: 1.51, 95\% CI 0.99-2.28; $p=0.049$ ), cataract (OR: 1.51, 95\% CI 1.09-2.10; $p=0.013$ ) and diabetic retinopathy (OR: 1.86, 95\% CI 1.32-2.62; $p<0.001$ ).

\section{Discussion}

The present study figures out that the prevalence of poor vision (types I and II, VA $1 / 20$ - 3/10) was $17.4 \%$ while that of blindness (types III, IV, and V, VA $<1 / 20$ ) was $12.3 \%$ in the worst eyes. Unsurprisingly, the dominating causes of poor vision and blindness were, from the most to the less encountered: cataract (29.7\%), sight threatening retinopathy (17.4\%), glaucoma (15\%).and maculopathy (14.5\%). These findings constitute good baseline data that will be helpful to evaluate the local effectiveness and impact of "vision 2020: the right to sight" programs.

The prevalence of blindness and poor vision found in this study are in keeping with the respective $17 \%$ and $18.8 \%$ reported by Tielsch et al. [2] who have worked on nursing home residents aged 40 years and above without seeking for their diabetic status. Contrarily, Narendran et al. [14] observed only a 3.5\% prevalence of bilateral blindness among 260 self-reported Indian diabetics. This huge discrepancy could be explained by the difference between our study population and that of the above-mentioned authors, as it has been strongly bolstered that blindness is significantly more preponderant in Blacks than in Whites [2]. What's more, the definitions of blindness and visual impairment we used were not exactly the same as the ones adopted by the previous authors. Indeed, the literature reveals that many factors may contribute to the variation of these prevalence rates, including age (old age especially), duration of diabetes (>10 years), ethnicity, occupation, cognitive function, metabolic control, skill of the examiner and methodology of examination among others [2-5,14,15]. Although women exhibit a tendency to be more blind and visually impaired than men, this has not yet been proven to be statistically significant $[2,14]$. As a matter of fact, this variation in prevalence rates of blindness and

Table 4 Intraocular pressure and visual acuity

\begin{tabular}{|c|c|c|c|c|c|c|}
\hline \multirow[b]{2}{*}{ Category of vision } & \multicolumn{3}{|c|}{$\begin{array}{l}\text { Right ocular pressure } \\
\text { n (\%) }\end{array}$} & \multicolumn{3}{|c|}{$\begin{array}{l}\text { Left ocular pressure } \\
\text { n (\%) }\end{array}$} \\
\hline & $\begin{array}{l}<20 \mathrm{mmHg} \\
(\mathrm{n}=347)\end{array}$ & $\begin{array}{l}21-30 \mathrm{mmHg} \\
(\mathrm{n}=48)\end{array}$ & $\begin{array}{l}>30 \mathrm{mmHg} \\
(\mathrm{n}=12)\end{array}$ & $\begin{array}{l}<20 \mathrm{mmHg} \\
(\mathrm{n}=346)\end{array}$ & $\begin{array}{l}21-30 \mathrm{mmHg} \\
(\mathrm{n}=48)\end{array}$ & $\begin{array}{l}>30 \mathrm{mmHg} \\
(\mathrm{n}=12)\end{array}$ \\
\hline Normal or near-normal vision & $267(76.9)$ & $30(62.5)$ & $6(50.0)$ & $267(77.2)$ & $31(63.3)$ & $5(41.7)$ \\
\hline Mild poor vision & $38(11.0)$ & $7(14.6)$ & $1(8.3)$ & $40(11.6)$ & $6(12.2)$ & $0(0)$ \\
\hline Severe poor vision & $9(2.6)$ & $2(4.2)$ & $0(0)$ & $8(2.3)$ & $2(4.1)$ & $1(8.3)$ \\
\hline Legal blindness & $10(2.9)$ & $1(2.1)$ & $0(0)$ & $8(2.3)$ & $2(4.1)$ & $1(8.3)$ \\
\hline Quasi-total blindness and total blindness & $23(6.6)$ & $8(16.6)$ & $5(41.7)$ & $23(6.6)$ & $8(16.3)$ & $5(41.7)$ \\
\hline$p$ value & 0.002 & & & 0.001 & & \\
\hline
\end{tabular}


Table 5 Cataract and visual acuity

\begin{tabular}{|c|c|c|c|c|}
\hline \multirow[b]{2}{*}{ Category of vision } & \multicolumn{2}{|c|}{$\begin{array}{l}\text { Right ocular cataract } \\
\text { n (\%) }\end{array}$} & \multicolumn{2}{|c|}{$\begin{array}{l}\text { Left ocular cataract } \\
\text { n (\%) }\end{array}$} \\
\hline & $\begin{array}{l}\text { Absent } \\
(n=286)\end{array}$ & $\begin{array}{l}\text { Present } \\
(n=121)\end{array}$ & $\begin{array}{l}\text { Absent } \\
(n=286)\end{array}$ & $\begin{array}{l}\text { Present } \\
(n=121)\end{array}$ \\
\hline Normal or near-normal vision & $235(82.2)$ & $68(62.5)$ & $242(84.6)$ & $61(50.4)$ \\
\hline Mild poor vision & $26(9.1)$ & $20(14.6)$ & $16(5.6)$ & $30(24.8)$ \\
\hline Severe poor vision & $4(1.4)$ & $7(4.2)$ & $4(1.4)$ & $7(5.8)$ \\
\hline Legal blindness & $5(1.7)$ & $6(2.1)$ & $7(2.5)$ & $4(3.3)$ \\
\hline Quasi-total blindness and total blindness & $16(5.6)$ & $20(16.6)$ & $17(5.9)$ & $19(15.7)$ \\
\hline$p$ value & $<0.0001$ & & $<0.0001$ & \\
\hline
\end{tabular}

visual impairment highlights the utmost need to standardise the different definitions and classifications regarding visual impairment and blindness, why not by consensually adopting those advocated by ICO [13].

Unsurprisingly, as depicted by some other authors [3,4,14-16], cataract, diabetic retinopathy and glaucoma were the most leading causes of visual impairment and blindness in our patients. The prevalence of cataract we observed (29.7\%) is lower than that reported by Rotimi et al. [3] (44.9\%), Funatsu et al. [4] (66.7\%), Bourne et al. [8] (56\%), and by Oye et al. [5] (62.1\%). But, it is similar to the $27.1 \%$ observed by Tielsch et al. [2], and higher than the $13.1 \%$ reported by Roaeid et al. [15] among Libyan diabetics. All these differences could be due to the varying mean age and duration of diabetes among the various study populations.

Meanwhile, the prevalence of diabetic retinopathy we found $(17.4 \%)$ is lower than what were encountered by Narendran et al. [14] (26.2\%), Roaeid et al. [15] (30.6\%) and by Funatsu et al. [4] (37\%), but comparable to the $17.9 \%$ revealed by Rotimi et al. [3] may be because our study populations are of the same race (sub-Saharan Black Africans) [2]. By contrast, our prevalence of diabetic retinopathy is higher than those reported by Tielsch et al. [2] and Bourne et al. [8]: 6.4\% and 5\% respectively. This difference is mainly explained by the fact that their study

\section{Table 6 Other causes of visual impairment}

\begin{tabular}{ll}
\hline Cause & Frequency (\%) \\
\hline Other maculopathies & $2(0.5)$ \\
Drusen & $2(0.5)$ \\
Pigment retinopathy & $3(0.7)$ \\
Papillary ischaemia & $11(2.7)$ \\
Vaso-oclusive eye disease & $10(2.5)$ \\
Age-related macular oedema & $8(2.0)$ \\
Central serous retinopathy & $1(0.3)$ \\
Vitreous degeneration & $3(0.7)$ \\
Hypertensive retinopathy & $20(4.9)$ \\
\hline
\end{tabular}

populations were not chosen on the basis of a known diabetic status. Although we did not seek for the risk factors for the development of diabetic retinopathy, it is well established that increased age, duration of diabetes (longer than 10 years), methods of diabetic control (HbA1c value), current insulin use, diabetic nephropathy, diabetic neuropathy, hypertension, systolic blood pressure, diastolic blood pressure, and arteriosclerosis obliterans are strongly associated with diabetic retinopathy, which is not the case for the sex $[3,4,14]$. Therefore, intensive blood glucose control, specifically in the early years of diagnosis (first 5 years), may reduce the risk for the development and progression of retinopathy and cataract. In this regard, early eye examination, preferably at first presentation of elevated blood glucose, is highly recommended [3].

Our prevalence of glaucoma was more than two times comparable to what has been reported by Bella et al. [9] who, after performing a prospective study of the intraocular pressure, fundus and perimetry in 307 Cameroonians aged 20-39 years irrespective of their diabetic status, found a prevalence of $5.8 \%$. Similarly, our prevalence of glaucoma was higher than those witnessed by Merle et al. [6] in Martinique (2.7\%), Ramakrishnan et al. [7] in India (2.6\%), and Bourne et al. [8] in Thailand (3.8\%). This discrepancy could be due to the fact that our study population appears to be older than those of the aforementioned studies. Consequently, our finding could be a true reflection of the prevalence of glaucoma in an aged population at risk especially in our milieu, as it has been clearly pointed out that this prevalence is much lower when working on a younger population of the same milieu [9]. However, the prevalence we obtained could be an overestimate of the real situation, given that we set the threshold for normal intraocular pressure at $20 \mathrm{mmHg}$ instead of $21 \mathrm{mmHg}$ as it was the case in other studies [6-8]. Even though this prevalence seems to be a little bit higher than what it must be, it is nonetheless suggestive of the great importance for a systematic screening of glaucoma in diabetic patients, specifically the aged ones. Tielsch et al. [2] did not show 
Table 7 Unadjusted correlates of causes of visual impairment

\begin{tabular}{|c|c|c|c|c|}
\hline Variable & Outcome & Unadjusted odds ratio & 95\% Confidence Interval & $p$ value \\
\hline \multicolumn{5}{|l|}{ Age } \\
\hline Less than 50 years old & & 1 & & \\
\hline \multirow[t]{5}{*}{50 years old and above } & Severely impaired vision ${ }^{*}$ & 6.84 & $3.41-13.73$ & $<0.001$ \\
\hline & Presence of glaucoma & 1.74 & $1.10-2.75$ & 0.017 \\
\hline & Presence of cataract & 4.29 & $2.85-6.45$ & $<0.001$ \\
\hline & Presence of diabetic retinopathy & 2.30 & $1.58-3.36$ & $<0.001$ \\
\hline & Presence of maculopathy & 1.43 & $0.92-2.23$ & 0.115 \\
\hline \multicolumn{5}{|l|}{ Sex } \\
\hline Male & & 1 & & \\
\hline \multirow[t]{5}{*}{ Female } & Severely impaired vision & 1.01 & $0.69-1.51$ & 0.939 \\
\hline & Presence of glaucoma & 1.02 & $0.69-1.51$ & 0.909 \\
\hline & Presence of cataract & 1.24 & $0.91-1.68$ & 0.166 \\
\hline & Presence of diabetic retinopathy & 0.66 & $0.48-0.92$ & 0.013 \\
\hline & Presence of maculopathy & 0.57 & $0.37-0.86$ & 0.008 \\
\hline \multicolumn{5}{|l|}{ Type of diabetes } \\
\hline Type 1 & & 1 & & \\
\hline \multirow[t]{5}{*}{ Type 2} & Severely impaired vision & 2.19 & $0.86-5.59$ & 0.099 \\
\hline & Presence of glaucoma & 1.81 & $0.76-4.29$ & 0.178 \\
\hline & Presence of cataract & 2.68 & $1.35-5.36$ & 0.005 \\
\hline & Presence of diabetic retinopathy & 0.64 & $0.37-1.11$ & 0.107 \\
\hline & Presence of maculopathy & 0.62 & $0.33-1.15$ & 0.131 \\
\hline \multicolumn{5}{|l|}{ Duration of diabetes } \\
\hline Less than 10 years & & 1 & & \\
\hline \multirow[t]{5}{*}{10 years and above } & Severely impaired vision & 1.97 & $1.31-2.94$ & 0.001 \\
\hline & Presence of glaucoma & 2.03 & $1.36-3.04$ & 0.001 \\
\hline & Presence of cataract & 2.03 & $1.49-2.76$ & $<0.001$ \\
\hline & Presence of diabetic retinopathy & 3.61 & $2.57-5.09$ & $<0.001$ \\
\hline & Presence of maculopathy & 4.16 & $2.62-6.59$ & $<0.001$ \\
\hline \multicolumn{5}{|c|}{ Presence of Hypertension } \\
\hline No & & 1 & & \\
\hline \multirow[t]{5}{*}{ Yes } & Severely impaired vision & 1.64 & $1.11-2.43$ & 0.014 \\
\hline & Presence of glaucoma & 1.77 & $1.19-2.65$ & 0.005 \\
\hline & Presence of cataract & 1.89 & $1.39-2.57$ & $<0.001$ \\
\hline & Presence of diabetic retinopathy & 2.29 & $1.66-3.17$ & $<0.001$ \\
\hline & Presence of maculopathy & 1.67 & $1.12-2.50$ & 0.012 \\
\hline
\end{tabular}

${ }^{*}$ Severely impaired vision: visual acuity $<1 / 10$.

any evidence of an association between diabetes and primary open angle glaucoma, but the relatively high prevalence of neovascular glaucoma (6.67\%) we encountered in patients exhibiting proliferative retinopathy in our study is a cause for concern.

Expectedly, we observed in this study that duration of diabetes was associated with glaucoma, cataract, diabetic retinopathy and maculopathy as it has already been pointed out in previous reports [3,4,16]. Poor blood sugar control is very frequent in African countries, leading to complications such as diabetes eye diseases [16]. Interestingly, Rotimi et al. found a low prevalence of diabetic retinopathy and cataract within the first 5 years following the diagnosis of diabetes in a cohort of West African diabetics, suggesting that intensive blood glucose control may reduce the risk of development and 
Table 8 Adjusted correlates of causes of visual impairment

\begin{tabular}{|c|c|c|c|c|}
\hline Variable & Outcome & Adjusted odds ratio & 95\% Confidence Interval & $p$ value \\
\hline \multicolumn{5}{|l|}{ Age } \\
\hline Less than 50 years old & & 1 & & \\
\hline \multirow[t]{4}{*}{50 years old and above } & Severely impaired vision ${ }^{*}$ & 6.03 & $2.98-12.20$ & $<0.001$ \\
\hline & Presence of glaucoma & 1.47 & $0.92-2.36$ & 0.109 \\
\hline & Presence of cataract & 3.45 & $2.21-5.38$ & $<0.001$ \\
\hline & Presence of diabetic retinopathy & 1.79 & $1.20-2.67$ & 0.004 \\
\hline \multicolumn{5}{|l|}{ Sex } \\
\hline Male & & 1 & & \\
\hline \multirow[t]{2}{*}{ Female } & Presence of diabetic retinopathy & 0.59 & $0.42-0.84$ & 0.003 \\
\hline & Presence of maculopathy & 0.54 & $0.35-0.83$ & 0.005 \\
\hline \multicolumn{5}{|l|}{ Type of diabetes } \\
\hline Type 1 & & 1 & & \\
\hline Type 2 & Presence of cataract & 1.15 & $0.53-2.49$ & 0.725 \\
\hline \multicolumn{5}{|l|}{ Duration of diabetes } \\
\hline Less than 10 years & & 1 & & \\
\hline \multirow[t]{5}{*}{10 years and above } & Severely impaired vision & 1.45 & $0.95-2.22$ & 0.085 \\
\hline & Presence of glaucoma & 1.76 & $1.16-2.68$ & 0.008 \\
\hline & Presence of cataract & 1.43 & $1.02-1.99$ & 0.035 \\
\hline & Presence of diabetic retinopathy & 2.94 & $2.06-4.20$ & $<0.001$ \\
\hline & Presence of maculopathy & 3.97 & $2.48-6.36$ & $<0.001$ \\
\hline \multicolumn{5}{|c|}{ Presence of Hypertension } \\
\hline No & & 1 & & \\
\hline \multirow[t]{5}{*}{ Yes } & Severely impaired vision & 1.31 & $0.87-1.98$ & 0.194 \\
\hline & Presence of glaucoma & 1.51 & $0.99-2.28$ & 0.049 \\
\hline & Presence of cataract & 1.51 & $1.09-2.10$ & 0.013 \\
\hline & Presence of diabetic retinopathy & 1.86 & $1.32-2.62$ & $<0.001$ \\
\hline & Presence of maculopathy & 1.33 & $0.87-2.03$ & 0.185 \\
\hline
\end{tabular}

${ }^{*}$ Severely impaired vision: visual acuity $<1 / 10$.

progression of retinopathy and cataract in these patients [3]. Similarly to a study aiming at the determination of the prevalence of visual impairment and selected eye diseases among diabetic patients in USA [17], we found that the likelihood for diabetic patients to have cataract and diabetic retinopathy was increased by patients' age greater than 50 years. Recently, Katte et al. have reported a significant rate of coincident diabetes and hypertension (3.9\% in men and $5.0 \%$ in women) in a self-selected semi-urban Cameroonian population [18]. Likewise, we found a high frequency of hypertension (39.6\%) in our study population and in accordance with previous reports [4,19-21], hypertension increased the risk of glaucoma, cataract and diabetic retinopathy.

A major limitation of this study is the fact that poor vision and blindness due to refractory errors were not analyzed. Not all patients said to have normal or near normal vision had a 10/10 visual acuity. Most of them were prescribed lenses, this suggesting a high prevalence of refractory errors among the estimated $73 \%$ of patients with normal or near normal vision. What's more, we did not perform a systematic evaluation of patients' visual fields when they were presenting with a high intra-ocular pressure in order to better define glaucoma. Nonetheless, throughout the recruitment, the ophthalmologic examination was carried out by experienced and well trained ophthalmologists so as to have reliable results. Further, the study was undertaken in a hospital environment with adequate and quality-assured equipment.

\section{Conclusion}

Poor vision and blindness are frequent among Cameroonian diabetic patients, and their causes are similar to those reported by various other surveys: cataract, glaucoma, diabetic retinopathy, maculopathy and other less causative ocular affections. Age, sex, duration of diabetes and 
hypertension are factors that variously impact upon the occurrence of poor vision and blindness among these patients. '2020 the right to sight" programs should thereby be focused at tackling and reducing the occurrence as well as the burden of such avoidable ocular affections in our milieu.

\section{Competing interests}

The authors declare that they have no competing interests.

\section{Authors' contributions}

Study conception and design: AMJ, AE, CEM. Data collection: AMJ, AE, CEM. Statistical analysis: JJNN, JRNN, AMJ. Drafting: AMJ, JRNN, JJNN. Critical discussion and manuscript revision: JJNN, JRNN, AMJ, YB, AE, CEM. All authors approved the final version of the manuscript.

\section{Acknowledgments}

The authors gratefully acknowledge all the patients who have accepted to take part in this study.

\section{Author details}

${ }^{1}$ Department of Internal Medicine and Specialties, Faculty of Medicine and Biomedical Sciences, University of Yaoundé I, Yaoundé, Cameroon.

${ }^{2}$ Department of Public Health, Faculty of Medicine and Biomedical Sciences, Yaoundé, Cameroon. ${ }^{3}$ Internal Medicine Unit, Edéa Regional Hospital, PO Box 100, Edéa, Cameroon. ${ }^{4}$ Medical Diagnostic Center, Yaoundé, Cameroon. ${ }^{5}$ Department of Ophthalmology, Faculty of Medicine and Biomedical Sciences, University of Yaoundé I, Yaoundé, Cameroon.

Received: 22 April 2014 Accepted: 19 March 2015

Published online: 08 April 2015

\section{References}

1. Resnikoff S, Pascolini D, Etya'ale D, Kocur I, Pararajaseqaram R, Pokharel GP, et al. Global data on visual impairment in the year 2002. Bull World Health Organ. 2004;82:844-51.

2. Tielsch JM, Javitt JC, Coleman A, Katz J, Sommer A. The prevalence of blindness and visual impairment among nursing home residence in Baltimore. N Engl J Med. 1995;332(18):1205-9.

3. Rotimi C, Daniel H, Zhou J, Obisesan A, Chen G, Chen Y, et al. Prevalence and determinants of diabetic retinopathy and cataracts in West African Type 2 diabetes patients. Ethn Dis. 2003;13 Suppl 2:S110-7.

4. Fanatsu H, Suto C, Horis S, Kitamura Y, Iwakiri T, Iwasaki M, et al. Prevalence of diabetic ocular complications and systemic factors. Nippon Ganka Gakkai Zasshi. 1993;97(8):947-54

5. Oye JE, Kuper H, Dineen B, Befidi-Mengue R, Foster A. Prevalence and causes of blindness and visual impairment in Muyuka: a rural health district in the South West Province, Cameroon. Br J Ophthalmol. 2006;90(5):538-42.

6. Merle H, Renard A, Donnio A, Richer R, Ayeboua L, Ensfelder G, et al. Glaucoma screening in Martinique. Results in 813 hospital employees. J Fr Ophthalmol. 2004;27(2):136-42.

7. Romakrishnan R, Nirmalan PK, Krishnadas R, Thulasiraj RD, Tielsch JM, Katz J, et al. Glaucoma in a rural population of Southern India: the Aravind comprehensive eye survey. Ophtalmology. 2003;110(8):1484-90.

8. Bourne RR, Sukudom P, Foster PJ, Tantisevi V, Jitapunkul S, Lee PS, et al. Prevalence of glaucoma in Thailand: a population based survey in Rom Klao District, Bangkok. Br J Ophthalmol. 2003:87(9):1069-74.

9. Bella-Hiag AL, Ebana Mvogo C, Ngosso A, Ellong A. Intraocular pressure in a young Cameroonian population. J Fr Ophtalmol. 1996;19(10):585-90.

10. Wild S, Rophic G, Green A, Sicree R, King H. Global prevalence of diabetes: estimates for the year 2030. Diabetes Care. 2004;27(5):1047-53.

11. King H, Aubert RE, Herman WH. Global burden of diabetes. 1995-2025. Prevalence, numerical estimates and projections. Diabetes Care. 1998;21(9):1414-31.

12. Jingi AM, Noubiap JJ, Ellong A, Bigna JJ, Mvogo CE. Epidemiology and treatment outcomes of diabetic retinopathy in a diabetic population from Cameroon. BMC Ophthalmol. 2014:14:19.

13. Visual Standards-Aspects and Ranges of Vision loss-Resolution adopted by the ICO, April 20, 2002. Available on http://www.icoph.org/downloads/ visualstandardsreport.pdf.
14. Narendran V, John RK, Raghuran A, Ravindran RD, Nirmalan PK, THulasiraj RD. Diabetic retinopathy among self-reported diabetics in Southern India: a population based assessment. Br J Ophthalmol. 2002;86:1014-8.

15. Roaeid RB, Kadiki OA. Prevalence of long-term complications among Type 2 diabetic patients in Benghazi, Libya. J Diabetol. 2011;3:5.

16. Kahloun R, Jelliti B, Zouali S, Attia S, Ben Yahia S, Resnikoff S, et al. Prevalence and causes of visual impairment in diabetic patients in Tunisia, North Africa. Eye (Lond). 2014;28(8):986-91.

17. Centers for Disease Control and Prevention (CDC). Prevalence of visual impairment and selected eye diseases among patients aged $\geq 50$ years with and without diabetes-United States, 2002. MMWR Morb Mortal Wkly Rep. 2004;53(45):1069-71.

18. Katte JC, Dzucie A, Sobngwi E, Mbong EN, Fetse GT, Kouam CK, et al. Coincidence of diabetes and hypertension in a semi-urban Cameroonian population: a cross-sectional study. BMC Public Health. 2014;14(1):696.

19. Raman R, Pal SS, Adams JS, Rani PK, Vaitheeswaran K, Sharma T. Prevalence and risk factors for cataract in diabetes: Sankara Nethralaya Diabetic Retinopathy Epidemiology And Molecular Genetics Study, report no. 17. Invest Ophthalmol Vis Sci. 2010;51(12):6253-61.

20. Langman MJ, Lancashire RJ, Cheng KK, Steward PM. Systemic hypertension and glaucoma: mechanisms in common and co-occurrence. $\mathrm{Br} J$ Ophthalmol. 2005;89(8):960-3.

21. Leske MC, WU SY, Hennis A, Connell AM, Hyman L, Schachat A. Diabetes, hypertension, and central obesity as cataract risk factors in a black population. The Barbados eye study. Ophthalmology. 1999;106(1):35-41.

\section{Submit your next manuscript to BioMed Central and take full advantage of:}

- Convenient online submission

- Thorough peer review

- No space constraints or color figure charges

- Immediate publication on acceptance

- Inclusion in PubMed, CAS, Scopus and Google Scholar

- Research which is freely available for redistribution

Submit your manuscript at www.biomedcentral.com/submit
C) Biomed Central 